\title{
Research on the Performance Evaluation and S\&T Resources Allocation of High-Tech Industry of China: Evidence Based on Three Different Economic Regions
}

\author{
Feng Feng ${ }^{1}$, Nan Zhou ${ }^{1}$, Leiyong Zhang ${ }^{1}$, Yuneng $\mathrm{Du}^{1} \&$ Lei Ma ${ }^{2}$ \\ ${ }^{1}$ The School of Public Affairs, University of Science and Technology of China, Hefei, China \\ ${ }^{2}$ The School of Management, University of Science and Technology of China, Hefei, China \\ Correspondence: Nan Zhou, School of Public Affairs, University of Science and Technology of China, Hefei, \\ China. Tel: 86-137-2105-8516. E-mail: munan11@mail.ustc.edu.cn
}

Received: January 5, 2013

Accepted: January 21, 2013 Online Published: February 16, 2013

doi:10.5539/ijbm.v8n5p13

URL: http://dx.doi.org/10.5539/ijbm.v8n5p13

\begin{abstract}
Taking the S\&T resources allocation as a key point, using Network DEA based on a parallel structure and the resources allocation technology, this paper evaluates and analyzes the performance level and the S\&T resources allocation of high-tech industry of nine provinces from Bohai Rim, Yangtze River Delta as well as Pearl River Delta in China. On the grounds of analyzing results, nine provinces can be classified as four types. Due to different features of each type, relative measures and suggestions can be raised. In the end, this paper takes Beijing for an example, displaying that how to improve the performance level of high-tech industry by redistributing the $S \& T$ resources, and putting forward a reasonable and effective program.
\end{abstract}

Keywords: high-tech industry, performance evaluation, S\&T resources allocation, network DEA

\section{Introduction}

As an important carrier of the technological innovation and a forward position of the scientific competition, high-tech industry plays an irreplaceable part in boosting the economy and enhancing the comprehensive strength of a country. High-tech industry, which always companied with high inputs, high outputs, high adventures and high profits, has been viewed as an important promotion to the national economy (Fang \& Zhang, 2009). Some studies showed that, in order to increase the performance of high-tech industry and optimize its structure, two methods could be used: accelerating the technological progress as well as appreciating the reasonable S\&T resources allocation (Liang et al., 2009). China, in the process of developing high-tech industry, only values the technological progress, but ignores the positive function of the reasonable S\&T resources allocation for improving the performance of high-tech industry. The S\&T resources allocation with a low efficiency not only wastes a variety of resources, but also brings down the performance of high-tech industry. Therefore, for China, a developing country with scarce resources, it is rather significant to research how to improve the performance level of high-tech industry by allocating S\&T resources reasonably and efficiently.

In recent years, analyzing and researching high-tech industry's performance or efficiency has become more and more popular in the academia. Long \& Ji (2005) using Data Envelopment Analysis (DEA) made an empirical analysis for the technological efficiency and the scale merit of high-tech industry of China. Lu (2008) employing DEA evaluated the efficiency of scientific input-output efficiencies of high-tech industry of China and analyzed their conditions of scale merit. Guan \& Chen (2009) calculated and analyzed the technological innovative efficiency of high-tech industry and indices of inefficient industries, showing that the whole innovative efficiency of high-tech industry of China needed to be further improved. Fan et al. (2011) through applying Stochastic Frontier Analysis, based on the panel data from 1996 to 2007, empirically analyzed the technological efficiency of high-tech industry of China. Furthermore, other scholars aimed at the efficiency problem of S\&T resources allocation of our country made extensive discussions and researches. For examples, $\mathrm{Li}$ et al. (2003) utilizing regression analysis quantitatively analyzed the factors affected by the efficiency of S\&T resources allocation of China. Wu \& Yang (2006) taking advantage of DEA model calculated the efficiency of S\&T resources allocation of high-tech industry of China, indicating that it was incongruous for the relationship 
between the high-tech industry's development and S\&T resources input. Yang \& Zhao (2007) based on the factor analysis empirically analyzed the ability to allocate S\&T resources of China and found out the advantages and disadvantages of S\&T resources allocation in different regions of China. Xu \& Zhang (2009) based upon DEA-Malmquist method assessed the efficiency of resources allocation of high-tech industry of China from 2002 to 2007, but she failed to provide concrete programs for resources allocation.

In practice, there is a close relationship between the performance evaluation and the resources allocation. On one hand, the results of the performance evaluation can provide references for how to allocate resources rationally in the future. It can be achieved through transforming the resources from low efficiency units to high efficiency units. On the other hand, reasonable resources allocation can acquire higher efficiencies in the performance evaluation. As a result, the model of the performance evaluation is viewed as a foundation of the model of resources allocation. However, according to review previous relevant literatures, we regrettably found that researches on high-tech industry were still in the stage of separating the connection between the industry performance and the resources allocation, which caused partial analyzing performance results, leaving out the factor of resources allocation. Thus, it was hard to enhance the performance level totally and excavate the development potential of high-tech industry.

Thinking of the above reasons, this paper in terms of the perspective of S\&T resources allocation reasonably, applies network DEA based on a parallel structure and the technology of resources allocation, chooses three different economic regions of China to evaluate and analyze the performance level of high-tech industry and the condition of S\&T resources allocation, and redistributes S\&T resources for inefficient provinces. Besides, the paper's innovations are as follows:

(1) With network DEA based on a parallel structure and the technology of resources allocation, the performance level of high-tech industry of nine provinces and their conditions of S\&T resources allocation are comprehensively analyzed in order to excavate the potentials of performance improvement of these provinces.

(2) Find out the inefficient provinces of S\&T resources allocation, and discover the reasons about the inefficiency.

(3) Using the resources allocation model, the technological resources of inefficient provinces can be reallocated and reasonable resources allocation projects also provided.

The paper is structured as follows: The first section not only introduces the significance of researching the performance level of high-tech industry by allocating S\&T resources reasonably, but also illustrates three innovations on the basis of reviewing relative literatures. DEA method and two models focusing on Kao's parallel DEA model and model for resources allocation are presented in the subsequent section. In the third section, the empirical research is developed from two aspects after collecting research areas and indices. One is the analysis based on three regions; the other is based on nine provinces. Conclusion and prospect are discussed in the final section.

\section{Method and Model}

\subsection{Method}

Data Envelopment Analysis (DEA) is a non-parametric technique to evaluate the relative efficiencies of a set of homogeneous decision marking units (DMUs) which convert multiple inputs to multiple outputs. It was first proposed by Charnes et al. (1978) and has been widely applied in many enterprises and not-for-profit organizations because of its advantages. For instance, it can deal with multiple dimensionalities and the efficiencies aren't affected by the dimensions chosen. At present, there are two popular research points about DEA theory and applications: (1) Network DEA. This concept was first introduced by Färe \& Grosskopf (2000), after that, Yang (2000), Castelli et al. (2004), Kao (2009) developed a special kind of network DEA models respectively, which could evaluate the DMUs with a parallel structure. This model can open the "black box" of DMUs to obtain more accurate efficiencies. (2) Resource allocation model. Previous studies about this item only dealt with reallocating resources between DMUs in organizational level. For instance, Beasley (2003) proposed a special DEA model for resources allocation and target setting about each DMU simultaneously, while Korhonen et al. (2004) developed a uniform model about resource allocation based on the efficiency analysis. What's more, Bi et al. (2011) provided an extended model about resources allocation and target setting for the organization in which each unit had parallel production lines. It stood on the side of a production unit allocating resources to production lines within the unit, while the previous studies allocated the resources in organization level. 


\subsection{Model}

Suppose there are $n$ independent DMUs, and each DMU consumes $m$ inputs $X_{\mathrm{ij}}(i=1, \ldots, m)$ to produce $s$ outputs $\mathrm{Y}_{\mathrm{rj}}(r=1, \ldots, s)$. Within DMUj, there are $p$ sub production units, named Sub-DMUs (SDMUs). It should be noted that the corresponding SDMUs within different DMUs are homogeneous. A parallel structure of a DMU is depicted in Figure 1 below. In this paper, DMUs represent nine provinces, while SDMUs represent five businesses in high-tech industry within each DMU, which is a parallel structure in nature. DMUo is the DMU under consideration.

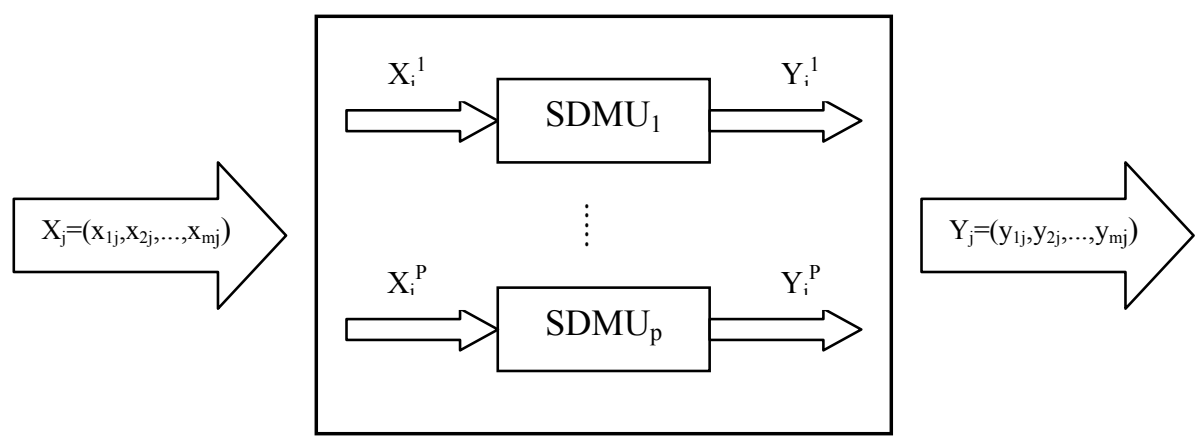

Figure 1. The sketch of a DMU with a parallel structure

\subsubsection{Kao's parallel DEA model}

$$
\begin{aligned}
& \min \sum_{k=1}^{p_{0}} s_{0}^{k} \\
& \text { s.t. } \sum_{i=1}^{m} v_{i} x_{i o}=1 \\
& \sum_{r=1}^{s} \mu_{r} y_{r o}^{k}-\sum_{i=1}^{m} v_{i} x_{i o}^{k}+s_{0}^{k}=0 \quad k=1, \ldots . . p_{o} \\
& \sum_{r=1}^{s} \mu_{r} y_{r j}^{k}-\sum_{i=1}^{m} v_{i} x_{i j}^{k}+s_{j}^{k}=0 \quad k=1, \ldots . . p_{j}, j=1, \ldots . ., j \neq 0 \\
& \forall \mu_{r}, v_{i \geq \varepsilon}
\end{aligned}
$$

$\varepsilon$ is a small non-Archimedean element. It's worth noting that model (1) measures the inefficiency score of DMUo and we have the score $\theta_{0}=1-\sum_{k=1}^{p_{0}} s_{0}^{k}$ as the efficiency of DMUo.

\subsubsection{Model for resources allocation}

Based on the Kao's model, Bi et al. (2011) proposed an extended DEA model for resources allocation considering the increment of inputs. We choose this model for our research about the resources allocation of high-tech industry out of at least three reasons. First of all, when evaluating the efficiency of DMUo, this model has great advantages which can improve the DMUo's efficiency while keeping the production technology unchanged. But the Kao's model underestimates DMUo's efficiency for not considering the resource allocation. Secondly, on the promise of efficiency maximizing, this model can provide the allocated scheme about assignable inputs within SDMUs. Thirdly, this model can provide the allocated scheme when the total amount of each assignable input is given to a certain level, and meanwhile it can set a reasonable target for the outputs. The resources allocation model is as follows: 


$$
\begin{aligned}
& \min \sum_{k=1}^{p_{O}} s_{0}^{k} \\
& \text { s.t. } \sum_{i=1}^{p_{O}} \beta_{i}^{k}=\alpha_{i} \quad i \in R \\
& \sum_{K=1}^{P_{O}} \pi_{r}^{k}=\phi_{r} \quad r=1, \ldots \ldots, s \\
& \sum_{i \in R} \alpha_{i} v_{i} x_{i o}+\sum_{i \notin R} v_{i} x_{i o}=1 \\
& \sum_{r=1}^{s} \pi_{r}^{k} \mu_{r} y_{r o}-\sum_{i \in R} \beta_{i}^{k} v_{i} x_{i o}-\sum_{i \notin R} v_{i} x_{i o}^{k}+s_{0}^{k}=0 \quad k=1, \ldots . . p_{o} \\
& \sum_{r=1}^{s} \mu_{r} y_{r j}^{k}-\sum_{i=1}^{m} v_{i} x_{i j}^{k}+s_{j}^{k}=0 \quad k=1, \ldots . . p_{j}, j=1, \ldots . n, j \neq 0 \\
& l_{i}^{k} \leq \frac{\beta_{i}^{k} x_{i o}}{x_{i o}^{k}} \leq u_{i}^{k} i \in R, k=1, \ldots \ldots \ldots, p_{0} \\
& \forall \mu_{r}, v_{i \geq \varepsilon}, \pi_{r}^{k} \geq 0
\end{aligned}
$$

$R$ indicates the index set of assignable inputs, i.e., the input $i$ can't be assigned when $i \notin R$. By definition, an input is assignable in the sense that the manager can redistribute this input among all SDMUs at random under the premise of constant sum of it. Suppose that the added inputs of SDMUk is $\left(\overline{x_{I o}}, \ldots \ldots . . ., \overline{x_{m o}}\right)$ based on the previous, and meanwhile, let $\overline{x_{i o}} / x_{i o}=a_{i} \quad(i=1, \ldots, m)$. To proceed, the decision variable $\beta_{i}^{k} \geq 0$ is defined to indicate the percentage changes of the $i$ th assignable inputs $(i \in R)$, which is allocated to SDMUk from one period to the next and the relationship $\sum_{k=1}^{p_{o}} \beta_{i}^{k}=\alpha_{i}$ is established in nature. Similarly, let $\sum_{k=1}^{p_{o}} \pi_{i}^{k}=\phi_{r}$ indicates the percentage changes of outputs of DMUo. This can be viewed as target setting for outputs. In addition, $I_{j}^{k}, u_{j}^{k}$ indicate the lower bound and the upper bound of input-change respectively, which should be consistent with the variation of the overall resources denoted by $a_{i}$. Obviously, model (2) is nonlinear and the equivalent linear model is as follows.

$$
\begin{aligned}
& \min \sum_{k=1}^{p_{O}} s_{0}^{k} \\
& \text { s.t. } \sum_{i=1}^{s} \delta_{r}^{k} y_{r o}-\sum_{i \in R} \gamma_{i}^{k} x_{i o}-\sum_{i \notin R} v_{i} x_{i o}^{k}+s_{0}^{k}=0 \quad k=1, \ldots . . p_{o} \\
& \sum_{i=1}^{s} u_{r} y_{r j}^{k}-\sum_{i=1}^{m} v_{i} k_{i j}^{k} \leq 0 \quad k=1, \ldots \ldots . p_{j}, j=1, \ldots, n, j \neq 0 \\
& \sum_{k=1}^{p_{O}} \gamma_{i}^{k}=\alpha_{i} v_{i}, \quad i \in R \\
& \sum_{k=1}^{p_{O}} \delta_{r}^{k}=\phi_{i} \mu_{r}, \quad \quad r=1, \ldots . . S \\
& \sum_{i \in R} v_{i} \alpha_{i} x_{i o}+\sum_{i \notin R} v_{i} x_{i o}=1 \\
& r_{i}^{k} l_{i}^{k} v_{i} \leq \gamma_{i}^{k} \leq u_{i}^{k} r_{i}^{k} v_{i}, i \in R, k=1, \ldots \ldots \ldots, p_{o} \\
& \forall \mu_{r}, v_{i \geq \varepsilon}, \delta_{r}^{k}, s_{o}^{k} \geq 0
\end{aligned}
$$

$r_{i}^{k}=x_{i o}^{k} / x_{i o}$ indicates the percentages of the inputs of SDMUk in the total DMUo. 


\section{Empirical Researches}

\subsection{Research Areas}

The paper chooses three different economic regions of China, which are Bohai Rim, Yangtze River Delta and Pearl River Delta, to analyze and research. The reason why we choose them is that these three regions possess vibrant and favorable economic development surroundings, powerful and competitive ability to scientific innovation, strong and prosperous high-tech industry. Bohai Rim includes five provinces, which are Beijing, Tianjin, Liaoning, Hebei and Shandong. Yangtze River consists of three provinces, which are Shanghai, Jiangsu and Zhejiang. Pearl River Delta refers to Guangdong province.

\subsection{Indices Collection}

Consulting "About the Notification of Statistical Classification Catalogue of High-Tech Industry Printed by the State Statistics Bureau", high-tech industry of China can be classified as five businesses, which are manufacture of medicines, manufacture of aircrafts and space crafts, manufacture of electronic equipment and communication equipment, manufacture of computers and office equipment as well as manufacture of medical equipment and measuring instrument. Since DEA is a method to evaluate the relative efficiencies of peer DMUs with multiple inputs and outputs in essence, the indicator system should consist of input and output indices. The detailed evaluation system is depicted in Figure 2 as follows.

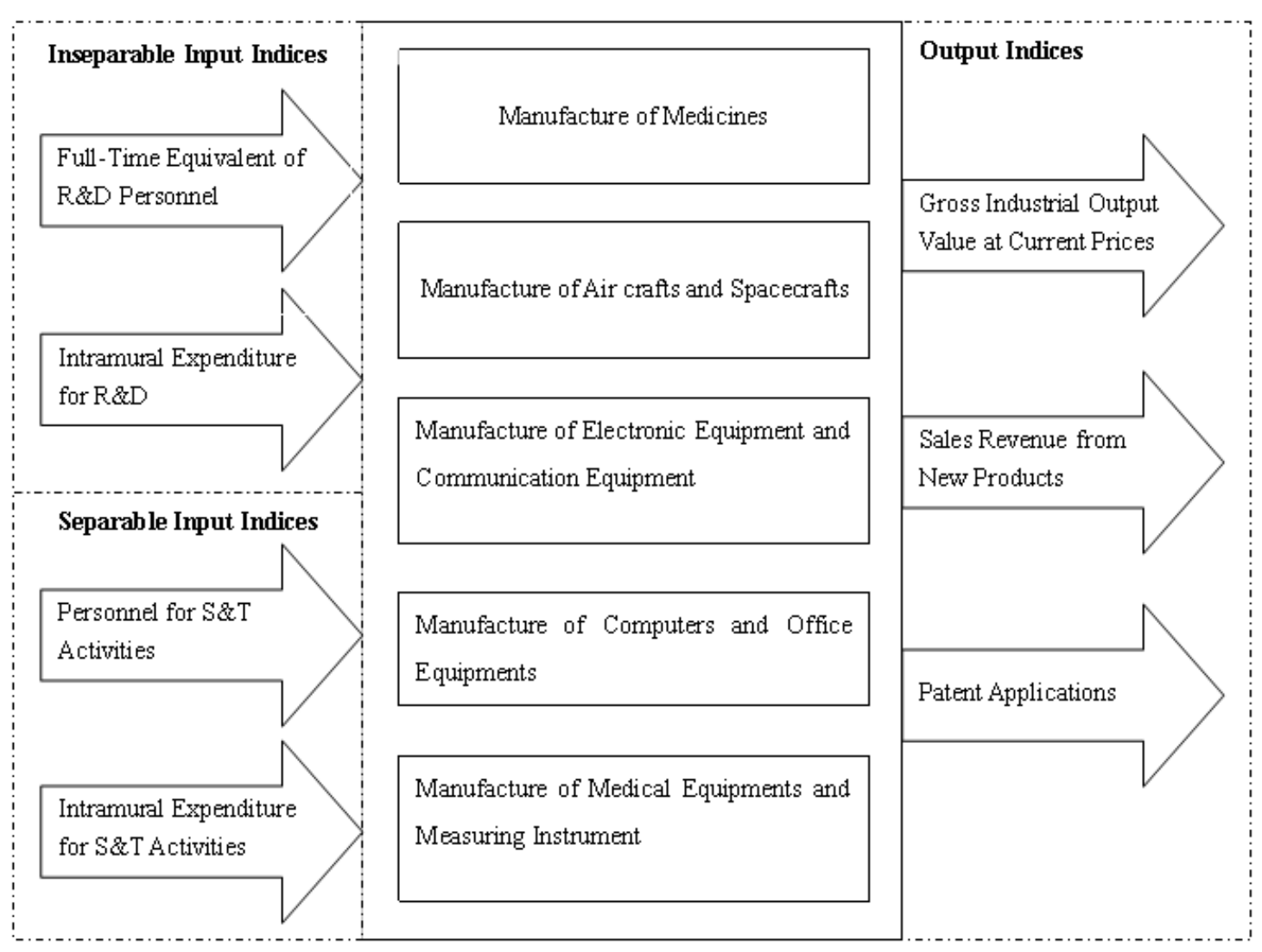

Figure 2. The evaluation system of input and output indices of high-tech industry

Generally speaking, S\&T activities in China mainly contain R\&D (research and development) activities, applications of $R \& D$ accomplishments as well as activities of $S \& T$ services. A crucial factor measuring the condition of S\&T activities is S\&T resources, which include three parts. (1) S\&T Human Resources (e.g. R\&D personnel, S\&T personnel); (2) S\&T Inputs (e.g. expenditure for S\&T activities, expenditure for R\&D activities); (3) S\&T Infrastructures (e.g. state key laboratories, science databases). In this paper, the authors take S\&T Human Resources and S\&T Inputs into consideration because these two types of S\&T resources are more important and common-used in analyzing resources allocation of high-tech industry. 


\subsubsection{Input Indices}

Different from other industries, high-tech industry emphasizes more on research and development (R\&D). For this reason, we select full-time equivalent of R\&D personnel and intramural expenditure for R\&D as inseparable input indices to represent essential features of personnel and expenditure used exclusively in the research and development of high-tech industry. Except for the inseparable input indices, the separable input indices, which are personnel for S\&T activities (not including scientists and engineers in S\&T personnel) and intramural expenditure for S\&T activities, are also selected out so as to be used to reallocate S\&T resource for inefficient provinces.

\subsubsection{Output Indices}

Generally speaking, there are two functions for the output indices of high-tech industry. One is that the economic value produces should be measured accurately. The other is that the creative capability and R\&D achievements of high-tech industry should be reflected clearly. In view of them, this paper selects gross industrial output value at current prices, sales revenue from new products and patent applications received as the output indices.

\subsection{Data Origin}

Taking into account of the input-output of five businesses of high-tech industry with a time lag and the lag period not accordant, the lag period in this paper is supposed almost two years for a unity (Feng et al., 2009; Feng et al., 2011). The data in this paper all originate from "China Statistics Yearbook on High Technology Industry". The input-output data are based on 2007 and 2009 respectively.

\subsection{Analysis of Empirical Results}

\subsubsection{Based on Three Regions}

In this section, the efficiencies of high-tech industry of nine provinces can be calculated by applying Kao's model (model 1) and the model for resources allocation (model 3) respectively. In model 3, full-time equivalent of R\&D personnel and intramural expenditure for $R \& D$ belong to $R$, and the other two indices are not in $R$. $a_{i}$ represents the increased proportion of $i$ compared to the base period. Set $\mathrm{a}_{\mathrm{i}}=1$ because we consider the problem of resources redistribution of high-tech industries on base period. As a specific allocated scheme, the equation $\sum^{p_{0}} \beta_{i}^{k}=1$ holds automatically. In addition, we assume that $I_{j}^{k}=0.7$ and $u_{j}^{k}=1.3$ for all the bounds when ${ }_{k}{ }_{k}$ pplying model 3, which means that the largest change ranges of assignable inputs for each SDMU are $30 \%$. Based on the principle of maximizing efficiency, model 3 can discover higher performances through resources allocation while model 1 will underestimate the efficiency for not considering this situation. As a result, the allocation efficiency can be defined as the efficiency ratio of model 3 to model 1 . If the allocation efficiency is lower than unity, DMUo is inefficient for resources allocation. It can reach a higher efficiency after redistributing assignable inputs. Otherwise, the efficiency of DMUo cannot be improved further while keeping the current production technology. The specific results were shown in Table 1.

Table 1. The efficiencies of high-tech industry of nine provinces calculated by two models

\begin{tabular}{ccccc}
\hline \multirow{2}{*}{ Rehai Rim } & $\begin{array}{c}\text { Efficiencies of } \\
\text { Model (1) }\end{array}$ & $\begin{array}{c}\text { Efficiencies of } \\
\text { Model (2) }\end{array}$ & $\begin{array}{c}\text { Efficiencies of } \\
\text { S\&T Resources }\end{array}$ \\
\hline \multirow{3}{*}{ Beijing } & 0.7507 & 0.8846 & 0.8486 \\
& Tianjin & 0.7308 & 0.7349 & 0.9944 \\
& Liaoning & 0.2790 & 0.2966 & 0.9407 \\
& Hebei & 0.2762 & 0.2762 & 1.0000 \\
& Shandong & 0.4608 & 0.4608 & 1.0000 \\
& Shanghai & 0.4935 & 0.4935 & 1.0000 \\
Yangtze River Delta & Jiangsu & 0.4700 & 0.4700 & 1.0000 \\
& Zhejiang & 0.4050 & 0.4050 & 1.0000 \\
& Guangdong & 0.4266 & 0.4266 & 1.0000 \\
\hline
\end{tabular}


To make a further illustration on discrepancies of high-tech industry's efficiency of nine provinces, we can calculate standard deviations of two models' efficiency. The results were shown in Table 2.

Table 2. The standard deviations of three regions based on two models

\begin{tabular}{rccc}
\hline Bypes & Bohai Rim & Yangtze River Delta & Pearl River Delta \\
\hline Model (1) & 0.2081 & 0.0374 & 0 \\
Model (2) & 0.2414 & 0.0374 & 0 \\
\hline
\end{tabular}

According to Table 1 and Table 2, we can analyze as follows:

Five provinces from Bohai Rim, whose efficiencies of high-tech industry had larger discrepancies, showed an imbalanced state of development. (1) The performance level of high-tech industry from Beijing and Tianjin were both higher, but the efficiencies of S\&T resources allocation were lower than 1 , which belonged to inefficient provinces. It was obvious that Beijing and Tianjin, possessing the solid economic strengths, abundant S\&T elites, predominant abilities to research and innovation, in the process of developing high-tech industry, seriously neglected the significance of allocating S\&T resources reasonably. (2) The efficiency of high-tech industry of Shandong province, compared to Beijing and Tianjin, was at a modest level, but its S\&T resources allocation proved to be efficient. (3) The performance level of high-tech industry from Liaoning and Hebei were both lower. However, the former belonged to the efficient province of S\&T resources allocation; the latter the inefficient one.

Compared to Bohai Rim, the high-tech industry in the provinces of Yangtze River Delta and Pearl River Delta developed in a balanced way, and their discrepancy of performance level were rather small. Besides, the efficiencies of resources allocation of these provinces all equaled 1, which meant that there hardly existed inefficient provinces. (1) The efficiency of high-tech industry of Zhejiang province was lower than Shanghai and Jiangsu. It was supposed that this condition mainly resulted from slow growth rates of high-tech industry as well as weak ability to innovation. (2) The efficiency of high-tech industry of Guangdong, which can be seen an only significant province in Pearl River Delta, was not ideal. There were two reasons explained better. Firstly, the areas in this province developed uneven. For example, some areas like Guangzhou, Shenzhen and Dongguan, had prosperous developments in high-tech industry, whereas the high-tech industry from the east and west areas as well as some mountains were lack of developing potentials. Secondly, it was deficient for the internal motivation promoting the development of high-tech industry in this province, and the ability to innovation independently still need to improve further.

\subsubsection{Based on Nine Provinces}

Taking into account of differences among three regions, the authors think that it is unnecessary to be based on three regions when providing relevant advices and suggestions in terms of the evaluated results and the efficiencies of resources allocation. It is more reasonable that we should make a classification research for nine provinces. Concrete analysis is as below.

Let the efficiencies of model 1 and model 3 as the horizontal axis and ordinate axis in Cartesian coordinate system respectively. Thus, the efficiencies of $\mathrm{S} \& \mathrm{~T}$ resources allocation of nine provinces were all drawn in Figure 3 called "the efficient scattered-dots diagram (short for ESD)". Each dot represented the efficiency of one province. The slant line at an angle of $45^{\circ}$ could be called "the efficient line of resources allocation (short for ELRA)", whose slope equaled 1. The efficient dots of all the provinces must be on the line or on the triangular area above the line. If a dot was on the line, we could say that the efficiency of S\&T resources allocation of the province represented by this dot proved to be efficient. Otherwise, it proved to be inefficient. 


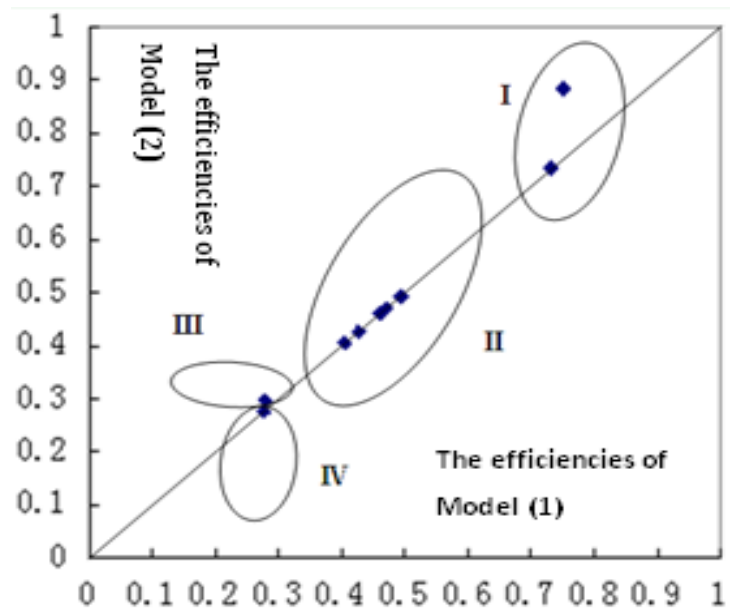

Figure 3. The efficient scattered-dots diagram (short for ESD) concerning nine provinces

Based on the distribution conditions about efficient dots of all the provinces, these provinces could be classified as four types. In Figure 3, we used four ellipses to indicate four different types. Noteworthy was the fact that the provinces in one type performed greater similarities in the aspects of the efficient features and the S\&T resources allocation.

Type I :There were two dots representing Tianjin and Beijing separately. The dot close to ELRA was Tianjin, and the other was Beijing. Their features displayed that the performance levels of high-tech industry were generally higher, but their S\&T resources allocations showed inefficient states. Therefore, we should not only accelerate the technical progress of high-tech industry of Beijing and Tianjin, but also pay much attention to allocate the S\&T resources reasonably in order to make further improvement of their performance levels of high-tech industry.

Type II : Along to ELRA the dots referred to Zhejiang, Guangdong, Shandong, Jiangsu and Shanghai successively. Their features displayed that the performance levels of high-tech industry were in a moderate position, but the S\&T resources allocations were efficient. As can be seen, five provinces presented perfect in the aspect of resources allocation, but the performance levels of high-tech industry should be made a further enhancement. Because of their efficient resources allocations, these provinces should focus on accelerating the technical progress. Through enhancing the capability of introducing, digesting and absorbing, they can promote the developments of high-tech industry, strengthen the innovation abilities and develop high-tech industry clusters with local features so as to improve the overall performance levels.

TypeIII: Liaoning province. The feature displayed that the performance level of high-tech industry was lower, and the S\&T resources allocation proved to be inefficient. Therefore, if the performance level of high-tech industry in Liaoning needs improving, two steps should be taken at least. One is to speed up the technical progress; the other is to reconfigure the S\&T resources reasonably.

TypeIV : Hebei province. The feature displayed that the performance level of high-tech industry was much lower, but the S\&T resources allocation proved efficient. As for Hebei, the upgrade space concerning the performance of high-tech industry should be rather considerable, so the emphasis should be placed in the aspect of quickening the technical progress and boosting high-tech industry. 


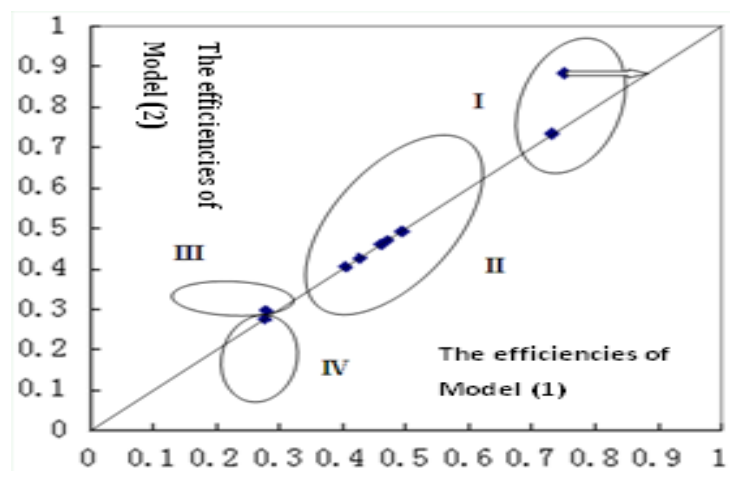

Figure 4. A path movement of the inefficient dot representing Beijing

According to the classification characters, the provinces in Type I and Type III (including Beijing, Tianjin and Liaoning), the S\&T resources allocation of which performed inefficient, need to reinforce the performance levels of high-tech industry considerably by improving the efficiencies of resources allocation. Consequently, it is very crucial to study how the S\&T resources are reconfigured so that the efficient scattered-dots might be close to ELRA or reserve on it eventually. This paper takes Beijing for an example (Figure 4) to show how the $\mathrm{S} \& \mathrm{~T}$ resources are reconfigured and how a reasonable and effective program on reconfiguring S\&T resources is put up.

Table 3. The efficiencies of S\&T resources allocation of five businesses in high-tech industry of Beijing

\begin{tabular}{lcc}
\hline \multicolumn{1}{c}{ Businesses } & $\begin{array}{c}\text { Before } \\
\text { Reallocation }\end{array}$ & $\begin{array}{c}\text { After } \\
\text { Reallocation }\end{array}$ \\
\hline Manufacture of Medicines & 0.3866 & 0.6377 \\
Manufacture of Air crafts and space crafts & 0.1035 & 0.1547 \\
Manufacture of Electronic Equipment and Communication Equipment & 1.0000 & 1.0000 \\
Manufacture of Computers and Office equipment & 1.0000 & 1.0000 \\
Manufacture of Medical equipment and Measuring Instrument & 0.3915 & 0.6651 \\
\hline
\end{tabular}

At the beginning, we should explore and analyze the inefficient reasons about S\&T resources allocation of Beijing (Table 3). This table displayed two groups of efficiencies about S\&T resources allocation of five businesses of high-tech industry in Beijing. One was the efficiency of S\&T resources calculated before reallocating, and the other group was the efficiency calculated after reallocating. Firstly, it should be pointed out that two groups of efficiencies of manufacture of electronic equipment and communication equipment as well as manufacture of computers and office equipment both equaled to 1, which demonstrated that S\&T resources allocation of these two businesses were efficient. Secondly, manufacture of medicines and manufacture of medical equipment and measuring instrument both belonged to inefficient businesses, the efficiencies of which were improved substantially after redistributing S\&T resources. Thirdly, the efficiencies of manufacture of air crafts and space crafts belonging to the inefficient business had a lower increase after redistributing S\&T resources. According to analyze and study the efficiencies of five businesses of high-tech industry of Beijing, it's not difficult to find that the inefficient reasons about S\&T resources allocation of Beijing resulted from manufacture of medicines, manufacture of air crafts and space crafts as well as manufacture of medical equipments and measuring instrument. For refining the inefficient conditions of S\&T resources allocation of Beijing, they should be reconfigured. A concrete allocation program can be seen in Table 4 . 
Table 4. A program of S\&T resources reallocation of Beijing

\begin{tabular}{ccccc}
\hline \multirow{2}{*}{ Businesses } & \multicolumn{2}{c}{ Personnel for S\&T Activities } & \multicolumn{2}{c}{$\begin{array}{c}\text { Intramural Expenditure for S\&T } \\
\text { Activities }\end{array}$} \\
\cline { 2 - 5 } & $\begin{array}{c}\text { Before } \\
\text { Reallocation }\end{array}$ & $\begin{array}{c}\text { After } \\
\text { Reallocation }\end{array}$ & $\begin{array}{c}\text { Before } \\
\text { Reallocation }\end{array}$ & $\begin{array}{c}\text { After } \\
\text { Reallocation }\end{array}$ \\
\hline $\begin{array}{c}\text { Manufacture of Medicines } \\
\text { Manufacture of Air crafts and } \\
\text { space crafts }\end{array}$ & $11.04 \%$ & $7.73 \%$ & $9.08 \%$ & $6.36 \%$ \\
$\begin{array}{c}\text { Manufacture of Electronic } \\
\text { Equipment and Communication } \\
\text { Equipment }\end{array}$ & $5.38 \%$ & $6.57 \%$ & $8.98 \%$ & $6.28 \%$ \\
$\begin{array}{c}\text { Manufacture of Computers and } \\
\text { Office equipment }\end{array}$ & $12.34 \%$ & $8.64 \%$ & $27.65 \%$ & $23.11 \%$ \\
$\begin{array}{c}\text { Manufacture of Medical equipment } \\
\text { and Measuring Instrument }\end{array}$ & $17.21 \%$ & $12.05 \%$ & $10.54 \%$ & $7.37 \%$ \\
\hline
\end{tabular}

Based on Table 4, personnel for S\&T activities and intramural expenditure for S\&T activities from manufacture of medicines, manufacture of air crafts and space crafts, manufacture of computers and office equipment as well as manufacture of medical equipment and measuring instrument, to varying degrees, all came down after reconfiguring S\&T resources. Furthermore, personnel for S\&T activities of manufacture of medical equipment and measuring instrument had a largest decrease, which was $5.16 \%$, and intramural expenditure for S\&T activities of manufacture of computers and office equipment declined the most, which was $4.54 \%$. However, personnel and intramural expenditure in manufacture of electronic equipment and communication equipment enhanced greatly, because this business was provided with further development potentials and spaces. As for Tianjin and Liaoning, we can also employ the same method.

After reconfiguring S\&T resources of inefficient provinces, we can draw another ESD describing the efficiencies of all the provinces researched (Figure 5). Compared to Figure 3, it can be seen that S\&T resources of Beijing, Tianjin and Liaoning have reached an efficient state, and the efficient scattered-dots were all on the ELRA.

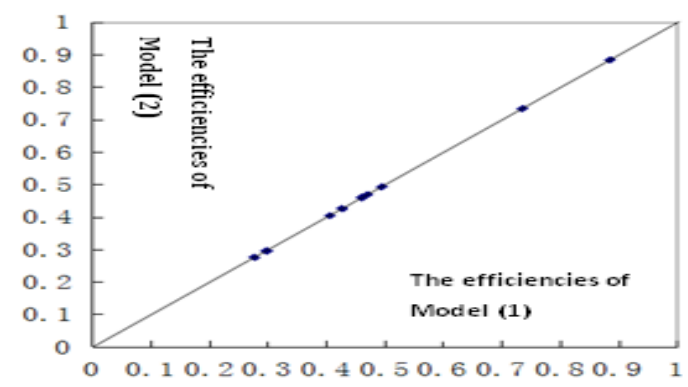

Figure 5. The ESD after reallocation concerning nine provinces

\section{Conclusions and Prospect}

Allocating S\&T resources reasonably plays a critical role in boosting the performance level of high-tech industry. On the grounds of $S \& T$ resources allocation rationally, this paper selects three different regions with rapid economic developments, which are Bohai Rim, Yangtze River Delta and Pearl River Delta, utilizing network DEA based on a parallel structure and the technology of resources allocation, to evaluate and analyze performance levels and efficiencies of S\&T resources allocation of nine provinces in three regions synthetically. In terms of research results, nine provinces can be classified as four types. Due to different features displayed by these four types, relative measures and suggestions can be put up with. Among inefficient provinces, Beijing is viewed as a typical example to demonstrate its inefficient reasons and an efficient program of reconfiguring S\&T resources. 
It should be noticed that this paper contains several limitations: (1) It's difficult to reflect the overall conditions of S\&T resources allocation of China when choosing only nine provinces to study. (2) The provinces on the ELRA have proved that they achieved a kind of efficient state on S\&T resources allocation, but the problem that how the efficiencies of S\&T resources of these provinces can be further improved is still in suspense. Therefore, follow-up studies should focus on two aspects. On one hand, according to expand the research scopes, the performance levels and S\&T resources allocation of high-tech industry of China can be demonstrated entirely. On the other hand, it is worth of researching how to make a further enhancement on the provinces whose efficiencies of S\&T resources allocation have been viewed as efficient.

\section{References}

Beasley, J. (2003). Allocating fixed costs and resources via data envelopment analysis. European Journal of Operational Research, 147, 198-216. http://dx.doi.org/10.1016/S0377-2217(02)00244-8

Bi, G. B., Ding, J. J., Luo, Y., \& Liang, L. (2011). Resource allocation and target setting for parallel production system based on DEA. Applied Mathematical Modelling, 35, 4270-4280. http://dx.doi.org/10.1016/j.apm.2011.02.048

Castelli, L., Pesenti, R., \& Ukovich, W. (2004). DEA-like models for the efficiency evaluation of hierarchically structured units. European Journal of Operational Research, 154, 465-476. http://dx.doi.org/10.1016/S0377-2217(03)00182-6

Charnes, A., Cooper, W. W., \& Rhodes, E. (1978). Measuring the efficiency of decision making units. European Journal of Operational Research, 2, 429-444. http://dx.doi.org/10.1016/0377-2217(78)90138-8

Fan, L. J., Li, N., \& Chen, Y. E. (2011). An empirical analysis on the regional disparity of technical efficiency in China's high-tech industries. Systems Engineering, 2, 56-62.

Fang, F. Q., \& Zhang, P. (2009). Analyzing input-output efficiency of the high-tech industries based on DEA. China Soft Science, 7, 48-55.

Färe, R., \& Grosskopf, S. (2000). Network DEA. Socio-Economic Planning Sciences, 34, 35-49. http://dx.doi.org/10.1016/S0038-0121(99)00012-9

Feng S. Y., \& Chen, D. Z. (2009). A study on the relationship between R\&D inputs and patents:panel data analysis of top global companies by R\&D investment. Studies in Science of Science, 10, 1500-1505.

Feng, F., Ma, L., \& Zhang, L. Y. (2011). Research on Efficiency of China's S\&T input-output in two-stage chain perspective: based on the data from 17 sub-industries of high-tech industry. Science of Science and Management of S. \& T., 32(10), 21-26.

Guan, J. C., \& Chen, K. H. (2009). Measuring innovation performance of Chinese high-tech industries. The Journal of Quantitative \& Technical Economics, 10, 19-33.

Kao, C. (2009). Efficiency measurement for parallel production systems. European Journal of Operational Research, 196, 1107-1112. http://dx.doi.org/10.1016/j.ejor.2008.04.020

Korhonen, P., \& Syrjänen, M. (2004). Resource allocation based on efficiency analysis. Management Science, 50(8), 1134-1144. http://dx.doi.org/10.1287/mnsc.1040.0244

Li, S. Z., Li, D. M., \& Tang, W. X. (2003). The quantitative analysis of S\&T resource allocation affecting Chinese districts. Scientific Management Research, 21(2), 60-63.

Liang, P., Liang, P. Y., \& Huang, X. (2009). High-tech industries innovation efficiency in china-an analysis of malmquist index. Industrial Economics Research, 3, 23-28.

Long, Y., \& Ji, X. F. (2005). The analysis of DEA concerning the technological improvement of high-tech industry. Statistics and Decision, 8, 72-74.

Lu, Y. M. (2008). The productivity evaluation of high-tech industry of China based on DEA. China Economist, $3,46-48$.

Wu, Y., \& Yang, H. J. (2006). DEA model for measuring the efficiency of S\&T resource allocation of high-tech industry based on R\&D knowledge stock. Science of Science and Management of S. \& T., 9, 28-32.

Xu, Y., \& Zhang, Q. Y. (2009). An empirical study of resource allocation efficiency of China's Hi-Tech industry: based on DEA-Malmquist index approach. Contemporary Finance \& Economics, 12, 74-79.

Yang, Y. P., \& Zhao, H. W. (2007). A positive Analysis on the Capacity of Regional Science and Technology Resource Allocation. Science and Technology Management Research, 12, 108-110.

Yang, Y. S., Ma, B. J., \& Koike, M. (2000). Efficiency measuring DEA model for production system with independent sub systems. Journal of the Operations Research Society of Japan, 43(3), 343-354. 